\title{
NÍVEIS DE MERCÚRIO EM ATUM SÓLIDO ENLATADO COMERCIALIZADO NA CIDADE DO RIO DE JANEIRO'
}

\author{
Allegra YALLOUZ², Reinaldo C. CAMPOS ${ }^{3},{ }^{*}$ \\ Andreía LOUZADA 4
}

\begin{abstract}
RESUMO
No presente trabalho, estudou-se o nível de mercúrio em atum sólido enlatado, comercializado na cidade do Rio de Janeiro. Foram analisadas 39 amostras, pertencente a 5 marcas e lotes distintos, utilizando-se a espectrometria de absorção atômica pela técnica de vapor-frio. Os resultados obtidos demonstraram que $53 \%$ das amostras apresentaram um teor acima do máximo recomendado, sendo que somente uma entre as cinco marcas estudadas apresentou todas as amostras com níveis dentro dos limites tolerados. Tais resultados demonstram a necessidade de um maior controle da qualidade destes produtos.
\end{abstract}

Palavras-chave : atum enlatado; mercúrio; absorção atômica; vapor-frio.

\section{SUMMARY}

TOTAL MERCURY LEVELS IN CANNED TUNA FISH COMMERCIALIZED AT THE RIO DE JANEIRO CITY, BRAZIL. The present study investigated the mercury levels in canned tuna fish, commercialized in the Rio de Janeiro city, Brazil. Thirty nine samples from five different makers were analyzed by cold vapor atomic absorption spectrometry. The results showed that $53 \%$ of the samples presented levels above the WHO (World Health Organization) recommended value, and only one from the five suppliers presented all their samples below this level. Such results indicate that it urges a better quality control for this food.

Keywords: CVAAS; mercury analysis; canned tuna fish.

\section{1 - INTRODUÇÃO}

As fontes de mercúrio para o meio ambiente podem ser classificadas como naturais ou antropogênicas. As primeiras são relativas, principalmente, a processos de desgaseificação da crosta terrestre [1]. Já as fontes antropogênicas são de várias origens: rejeitos de indústrias de cloro-soda, de equipamentos elétricos e eletrônicos, pesticidas e fungicidas, tintas, etc. No Brasil, destacou-se a atividade garimpeira, principalmente na Região Amazônica [5].

É importante ressaltar que, dependendo das condições físico-químicas, o mercúrio que é introduzido no

\footnotetext{
${ }_{1}^{1}$ Recebido para publicação em 30/01/98. Aceito para publicação em 11/04/01.

${ }^{2}$ Doutor em Química Analítica pela PUC-Rio, pesquisador do CETEM-CNPq. Rua 4, quadra D, Cidade Universitária, Ilha do Fundão. CEP 21941-590.

${ }^{3}$ Professor Adjunto do Departamento de Tecnologia de Aimentos, UNIRIO e Professor Associado no Departamento de Química PUC-

Rio. Rua Marquês de São Vicente, 225. CEP 22453-900.

${ }^{4}$ Nutricionista, formada pela UNIRIO.

${ }^{*}$ A quem a correspondência deve ser enviada.
}

meio ambiente pode se transformar em diferentes espécies. Cada uma apresenta potencial tóxico bem diferenciado podendo, inclusive, ocorrer interconversão entre elas $[1,3,7]$. As espécies de maior interesse no estudo do impacto ambiental são o mercúrio elementar, o mercúrio iônico e os organo-mercuriais, com destaque para o metilmercúrio. Este último é o principal responsável pela intoxicação do ser humano através de pescado [9], já que estudos comprovam que de $80 \%$ a $95 \%$ do teor de mercúrio total encontrado em peixes se encontram na forma metilada. Mesmo em regiões com níveis normais em águas, podem ser observados teores relativamente altos de mercúrio em peixes pois, ao ser incorporado na cadeia trófica, o mercúrio é biomagnificado e bioacumulado, devido à sua longa meia-vida nos organismos (640 a 1200 dias). Portanto, observa-se com maior freqüência altos teores de $\mathrm{Hg}$ em peixes carnívoros e grandes [6]. No homem, a absorção intestinal do metil-mercúrio é maior que $95 \%$ e sua meia-vida biológica para eliminação fica em torno de 70 dias. Quando é absorvido, acumula-se nos rins, no fígado e no sistema nervoso central (SNC), atuando como inibidor enzimático, inativando proteínas pelo bloqueio de radicais $\mathrm{SH}[9]$.

As manifestações clínicas da intoxicação por mercúrio podem ser agudas ou crônicas. A aguda, devido à ingestão de alimentos contaminados por metil-mercúrio, produz um quadro que varia de leve a letal, com vômitos freqüentes, tremores, ataxia, parestesia, paralisia, perda de voz, cegueira, coma e morte. A intoxicação crônica afeta principalmente o SNC, causando parestesia, ataxia, dificuldade de articular palavras, sensação generalizada de fraqueza, fadiga e incapacidade de concentração, perda de visão e audição, coma e morte [9]. Os efeitos clínicos, porém, não são imediatos. No caso de exposição ambiental, o período latente pode chegar a 10 anos, e, é inversamente proporcional ao nível de exposição. Há relatos de casos, nos quais os sintomas clínicos pioram com o tempo e continuam, apesar de se reduzir ou interromper a exposição. O metil-mercúrio tem efeito feto-tóxico, com alterações irreversíveis para o feto, mesmo sem o aparecimento de sintomas na mãe. Os sintomas observados em neonatais e crianças, devido à exposição pré-natal, são a paralisia cerebral, distúrbios mentais, retardamento do desenvolvimento de várias funções psicomotoras, convulsões, cegueira e má-formação interna e externa dos ouvidos $[1,9]$.

O risco de intoxicação pela ingestão de peixe contaminado depende de alguns fatores, sendo que o teor 
de mercúrio, a quantidade ingerida e a freqüência de ingestão são determinantes para a acumulação de metilmercúrio no organismo humano $[1,7,9]$. O limite máximo para mercúrio total em peixe, estabelecido pela O.M.S.(Organização Mundial de Saúde) é de $0,5 \mu \mathrm{g} / \mathrm{g}$, para um consumo semanal de 400 gramas. Cuidados especiais, no entanto, devem ser tomados com grupos de risco, como gestantes, pós-gestantes e recém-nascidos. Efeitos sobre o SNC são documentados na literatura $[1,9]$ para ingestão diária de $3 \mathrm{mg}$ de mercúrio/ $\mathrm{Kg}$ em adultos.

Dentre os métodos atualmente usados para a determinação de mercúrio, pode-se destacar a espectrometria de absorção atômica pela técnica do vapor frio, que se popularizou devido a facilidade de operação, boa sensibilidade e baixo custo, quando comparada com as outras técnicas [4]. A técnica de vapor-frio consiste na redução, a mercúrio elementar, do mercúrio presente na solução resultante da digestão prévia da amostra, com posterior arraste do vapor formado para a cela de absorção postada no caminho ótico do equipamento de absorção atômica $[2,8]$. O sinal de absorvância observado é proporcional à concentração do mercúrio na solução.

O objetivo do presente trabalho foi de verificar os níveis de mercúrio em atum sólido enlatado disponível para consumo na cidade do Rio de Janeiro.

\section{2 - MATERIAIS E MÉTODOS}

\section{1 - Amostragem}

Adquiriram-se 39 latas de atum sólido de 5 marcas de grande consumo em diferentes supermercados da Zona Sul e Norte da cidade do Rio de Janeiro, no período de abril/maio de 1996. Buscou-se a coleta de diferentes lotes de fabricação e, quando tal não se encontrava especificado, optou-se por datas de fabricação diferentes. Na Tabela 1 encontra-se o quadro de amostragem executado.

TABELA 1. Amostragem de atum sólido enlatado $\left(n^{0}\right.$ de latas analisadas)

\begin{tabular}{cccc}
\hline marca & lote & / & data \\
& I & II & $\begin{array}{c}\text { fabricação } \\
\text { III }\end{array}$ \\
\hline A & 3 & 3 & 3 \\
B & 3 & 3 & 3 \\
C & 3 & 3 & 3 \\
D & 3 & 3 & - \\
E & 3 & 3 & - \\
\hline
\end{tabular}

\section{2 - Análise das amostras}

\subsection{1 - Tratamentos preliminares}

De cada lata a ser analisada, o excesso de líquido em seu interior foi escorrido e alíquotas com massa de $2 \mathrm{~g}$ foram exatamente pesadas, usando pinça com as pontas recobertas com fita de teflon, sendo este recobrimento trocado previamente à manipulação de cada nova lata. O excesso de água e óleo das amostras foi retirado, pressionando-se levemente as alíquotas com lenços de papel absorvente.

\subsection{2 - Digestão}

O método de digestão que foi usado é uma adaptação do método recomendado pela A.O.A.C. [2] e usado rotineiramente no laboratório de absorção atômica da PUC-Rio: as amostras pesadas diretamente nos tubos de digestão, foram adicionados $15 \mathrm{~mL}$ de mistura sulfonítrica $1: 1$ com $0,1 \%$ de pentóxido de vanádio $\left(\mathrm{V}_{2} \mathrm{O}_{5}\right)$. Após uma hora de repouso, adicionaram-se 3 gotas de antiespumante, e a mistura foi submetida a aquecimento a $95^{\circ} \mathrm{C}$, em bloco digestor por 1 hora. Após resfriamento, cada amostra foi transferida para balão volumétrico de $100 \mathrm{~mL}$, com o auxílio de água deionizada. Após homogeneização e resfriamento, foram adicionados $15 \mathrm{~mL}$ de solução $5 \%$ de permanganato de potássio. Esta solução foi deixada em repouso, no aguardo da determinação de mercúrio pela técnica de vapor-frio.

\subsection{3 - Determinação}

O mercúrio foi determinado em um espectrofotômetro de absorção atômica Varian AA6, equipado com kit gerador de mercúrio Varian VGA 96 modificado [2]. O excesso de oxidante foi previamente reduzido com cloridrato de hidroxilamina $20 \% \mathrm{~m} / \mathrm{v}$, imediatamente antes da determinação. Todos os reagentes utilizados foram de grau analítico, e a água, deionizada.

\subsection{4 - Garantia de qualidade analitica}

Todo o material de vidro foi lavado sucessivamente com água e detergente, deixado pernoitar em solução de ácido nítrico $10 \%$ e, finalmente enxaguado com água deionizada. O procedimento de analise foi previamente testado, usando-se material certificado de referência [2], sendo este procedimento repetido ao longo deste trabalho. Na análise do material certificado DORM1 (Dog-fish, Nacional Research Council, Canadá), obteve-se como resultado o teor de $800 \pm 100 \mathrm{ng} / \mathrm{g}(\mathrm{n}=3)$, em concordância com o valor certificado de $798 \pm 74$ Cada batelada de amostras foi ainda acompanhada por uma amostra controle, i.e. uma amostra escolhida aleatoriamente, analisada previamente $(n=10)$ e ao longo das análises (Figura 1). De cada lata aberta, foram analisadas duplicatas, que apresentaram desvios sempre menores que $9 \%$.

A Figura 1 mostra os resultados relativos à análise de 10 alíquotas de uma mesma lata de atum sólido, realizada com vistas à investigação da homogeneidade do material e influência do procedimento de retirada do excesso de líquido na reprodutibilidade, uma vez que as amostras foram analisadas in natura. Os resultados indicam uma boa repetibilidade, com um coeficiente de variação de $9 \%$. A análise da amostrain natura se faz necessária, por ser o mercúrio e seus compostos relativamente voláteis, não sendo recomendado a secagem prévia da amostra; quando necessário, o teor de umidade deve ser determinado em alíquota à parte. 
Não foi esse o caso do presente trabalho, até porque os valores limite das agências reguladoras relativos ao teor máximo de mercúrio em peixes são definidos em base úmida.

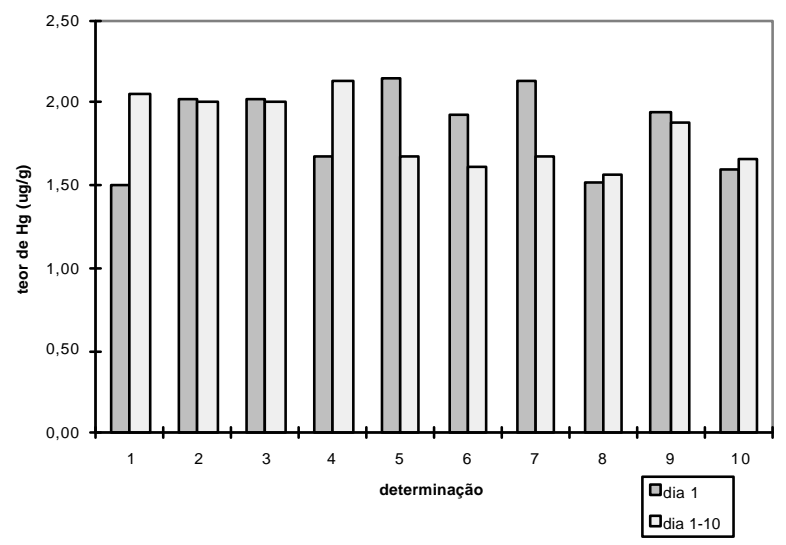

FIGURA 1. Determinação de mercúrio em alíquotas diferentes de uma mesma lata, analisadas 10 vezes num mesmo dia e ao longo do experimento como amostra testemunho (amostra não-homogeneizada).

\section{3 - RESULTADOS e DISCUSSÃO}

Os resultados obtidos se encontram na Tabela 2, organizados segundo a marca-lote .

TABELA 2. Níveis de mercúrio(mg/g peso fresco) em atum sólido enlatado(duplicatas) comercializado no Rio de Janeiro

\begin{tabular}{|c|c|c|c|c|c|c|c|c|}
\hline marca-lote & lata & 1 & Lata & 2 & lata & 3 & média & \pm desvio \\
\hline A-I & 1,73 & 1,59 & 1,63 & 1,47 & 1,36 & 1,49 & 1,55 & $\pm 0,13$ \\
\hline A-II & 0,46 & 0,41 & 0,48 & 0,39 & 0,44 & 0,40 & 0,43 & $\pm 0,04$ \\
\hline A-III & 0,07 & 0,11 & 0,27 & 0,24 & 0,19 & 0,21 & 0,18 & $\pm 0,07$ \\
\hline B-I & 0,26 & 0,27 & 0.48 & 0,50 & 0,28 & 0,29 & 0,35 & $\pm 0,11$ \\
\hline B-II & 0.30 & 0,31 & 0,42 & 0,49 & 0,26 & 0,26 & 0,34 & $\pm 0,09$ \\
\hline B-III & 0,34 & 0,35 & 0,28 & 0,31 & 0,26 & 0,27 & 0,30 & $\pm 0,03$ \\
\hline C-I & 0,64 & 0,63 & 1,01 & 0,96 & 0,99 & 0,93 & 0,86 & $\pm 0,18$ \\
\hline C-II & 0,32 & 0,29 & 0,50 & 0,46 & 0,37 & 0,36 & 0,38 & $\pm 0,08$ \\
\hline C-III & 0,77 & 0,70 & 0,88 & 0,90 & 0,84 & 0,89 & 0,83 & $\pm 0,08$ \\
\hline$D-1$ & 0,73 & 0,74 & 0,61 & 0,67 & 0,60 & 0,55 & 0,65 & $\pm 0,08$ \\
\hline D-II & 1,14 & 1,08 & 1,35 & 1,28 & 0,42 & 0,54 & 0,97 & $\pm 0,40$ \\
\hline E-I & 0,52 & 0,56 & 0,93 & 0,87 & 1,63 & 1,73 & 1,04 & $\pm 0,52$ \\
\hline E-II & 0,59 & 0,52 & 0,73 & 0,75 & 0,54 & 0,56 & 0,62 & $\pm 0,10$ \\
\hline
\end{tabular}

Na Tabela 2 destacam-se os altos valores encontrados, com cerca de $53 \%$ das amostras apresentando teores acima do máximo tolerado pela legislação para mercúrio em tecido muscular de peixe. Na Figura 2, onde são mostrados os valores médios de cada lote das diferentes marcas analisadas, em comparação com os valores máximo recomendados e tolerados, observa-se que também $53 \%$ dos lotes apresentam-se acima do valor máximo recomendado.
FIGURA 2. Teor médio apresentado pelas diferentes marcas e lotes analisados

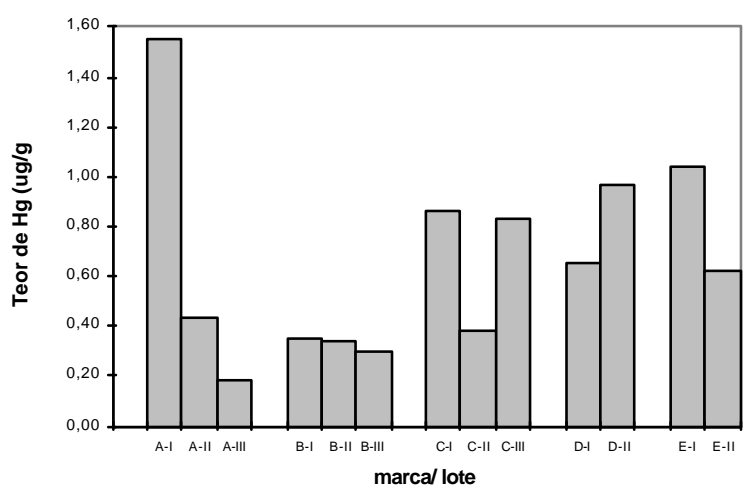

Foi observado que, para marca A, os 3 lotes analisados apresentaram níveis significativamente distintos, sendo que os dois com os maiores teores vieram com especificação de procedência do México, enquanto o terceiro lote apresentava especificação de procedência da Tailândia. A marca B apresentou todos os teores abaixo do máximo tolerado, sendo que todos seus lotes apresentavam especificação de procedência do Brasil. Na marca C, verificaram-se dois lotes acima do máximo tolerado, enquanto que todos os lotes tomados para a análise das marcas D e E mostraram valores acima daquele máximo. As marcas $\mathrm{D}$ e $\mathrm{E}$ foram as que apresentaram maior variabilidade entre latas de um mesmo lote.

\section{4 - CONCLUSÕES}

Os resultados indicaram altos teores de mercúrio nas amostras analisadas, principalmente aquelas procedentes do México, Venezuela (marca D) e Peru (marca E). Estes resultados indicam a necessidade de um maior controle da qualidade destes produtos, mesmo sabendo-se que tal alimento não faz parte da dieta diária da maioria da população brasileira. Entretanto, casos específicos de alto consumo podem estar ocorrendo, o que significaria riscos para estes indivíduos, em especial àqueles que fazem parte de subgrupos especialmente sensíveis, como crianças e gestantes.

\section{5 - REFERÊNCIAS BIBLIOGRÁFICAS}

[1] Agengy for Toxic Substances and Disease Registry - ASTDR. Toxicological profile for mercury. Atlanta, U.S.Public Health Service, 1989.

[2] CAMPOS, R.C. Estudo da determinação de mercúrio por espectrometria de absorcão atômica sem chama pela técnica do vapor frio. 1980, Dissertação de Mestrado. Departamento de Química, PUC-RIO.

[3] CASARETT E DOULL'S. Toxicology, the basic science of poisons. 4.Ed, N.York, Pergamon Press, 647-651, 1991.

[4] CHILOV,S. Determination of small amounts of mercury. Talanta, v.22, p.205-232, 1975.

[5] LACERDA, L.D., Solomons, W. Mercúrio na Amazônia: Uma bomba relógio química? Rio de Janeiro, CETEM/CNPq, 1992, 78p. 
[6] PETERSON, C.L., KLAWE, W.L., SHARP. G.D. Mercury in tunas:a review. Fishery Bulletin, v.71, n.3, p.603-613, 1973.

[7] TSALEV, D.L. , ZAPRIANOV. Z.K. Atomic absorption spectrometry in occupational and environmental health practice. 2.Ed, Florida, CRC PRESS, 1985, vol.I
[8] WELZ, B. Atomic absorption spectrometry, 2.ed., Weinheim, VHC, 1985, 506p.

[9] WORD HEALTH ORGANIZATION (WHO). Environmental health criteria for methyl mercury. Geneve, International Programme on Chemical Safety,1990. 144p. 